\title{
Cutaneous nociception and neurogenic inflammation evoked by PACAP38 and VIP
}

\author{
Henrik Winther Schytz $\cdot$ Helle Holst $\cdot$ \\ Lars Arendt-Nielsen · Jes Olesen • Messoud Ashina
}

Received: 2 March 2010/Accepted: 6 April 2010/Published online: 9 May 2010

(C) Springer-Verlag 2010

\begin{abstract}
Pituitary adenylate cyclase-activating peptide38 (PACAP38) and vasoactive intestinal peptide (VIP) belong to the same secretin-glucagon superfamily and are present in nerve fibers in dura and skin. Using a model of acute cutaneous pain we explored differences in pain perception and vasomotor responses between PACAP38 and VIP in 16 healthy volunteers in a double-blind, placebocontrolled, crossover study. All participants received intradermal injections of 200 pmol PACAP38, $200 \mathrm{pmol}$ VIP and placebo into the volar forearm. Measurements included pain intensity on a visual analog scale (VAS), blood flow by laser Doppler flowmetry, visual flare and wheal. Pain intensities after PACAP38 and VIP were mild and limited to a short time of about $100 \mathrm{~s}$ after injection. The area under the VAS-time curve was larger following PACAP38 $(P=0.004)$ and VIP $(P=0.01)$ compared to placebo. We found no statistical difference in pain perception between PACAP38 and VIP. Skin blood flow increase, flare and wheal were larger after both PACAP38 $(P=0.011)$ and VIP $(P=0.001)$ compared to placebo. VIP induced a considerably larger increase in skin blood flow, flare and wheal than PACAP38 $(P=0.002)$. In conclusion, we found that peripheral nociceptive cutaneous
\end{abstract}

H. W. Schytz · J. Olesen · M. Ashina ( $₫)$

Department of Neurology, Faculty of Health Sciences,

Danish Headache Center, Glostrup Hospital,

University of Copenhagen, Glostrup,

2600 Copenhagen, Denmark

e-mail: ashina@dadlnet.dk

H. Holst · L. Arendt-Nielsen

Laboratory for Experimental Pain Research,

Department of Health Science and Technology,

Center for Sensory-Motor Interaction (SMI),

Aalborg University, Aalborg, Denmark responses elicited by PACAP38 and VIP are similar in healthy volunteers. This suggests that acute pain and vasomotor responses following intradermal injections of PACAP38 and VIP are primarily mediated by VPAC receptors.

Keywords Cutaneous pain model - PACAP38 ·

VIP · Pain · Neurogenic inflammation ·

Mast cell degranulation - Migraine without aura

\section{Introduction}

Pituitary adenylate cyclase-activating peptide (PACAP) and vasoactive intestinal peptide (VIP) are members of the secretin-glucagon superfamily of peptides and involved in various biological functions, including nociceptive transmission [1]. PACAP and VIP are functionally linked as both peptides bind to the VPAC1 and VPAC2 receptors with equal affinity, but PACAP also selectively binds to the PAC1 receptor [2].

The role of PACAP38, the most predominant PACAP form in most tissues [3-6], has been explored in an experimental human migraine model [7-9]. It was shown that intravenous administration of PACAP38 induced acute headache and delayed migraine-like attacks in migraine sufferers [9]. In contrast, VIP infusion only induced very mild headache during infusion and no delayed migrainelike attacks [8]. These results suggest that PACAP38induced migraine could be due to the selective activation of the PAC1 receptor by PACAP38. The major limitation of the human migraine model is that peripheral nociceptive mechanisms in the perivascular space, such as neurogenic inflammation and mast cell degranulation, cannot be visualized. Furthermore, following intravenous administration it 
is unknown to what extent the experimental drug reaches sensory nerve endings in perivascular space relevant for head pain. Given that skin nociceptors show property characteristics similar to dural nociceptors $[10,11]$, the cutaneous model of acute pain offers a method to compare pain mechanisms between PACAP38 and VIP in an isolated skin area under controlled conditions. The cutaneous application of algogenic substances may result in neurogenic inflammation shown as increased blood flow and flare, which are caused by activation of nociceptors and the subsequent release of substance P (SP) and CGRP [12]. Furthermore, mast cell degranulation can be investigated by a relatively simple analysis of skin wheal reponse [13], which reflects a localized vasodilatation and leakage of plasma proteins from postcapillary venules [14].

The aims of the present study were, in a double-blind placebo-controlled crossover study, to elucidate the differences between PACAP38 and VIP in generating (1) cutaneous pain; (2) neurogenic inflammation, measured by increases in skin blood flow and flare; (3) mast cell degranulation, measured by increase in skin wheal. We hypothesized that PACAP38 would induce more pain, neurogenic inflammation and mast cell degranulation compared to VIP and placebo.

\section{Methods}

Sixteen healthy subjects ( 8 females and 8 males), mean age 27 years (range 19-45), were recruited. The subjects were in good health condition and did not suffer from any peripheral vascular disease or neurological or dermatologic disorder. All subjects were non-smokers and did not take any daily medication apart from oral contraceptives. All females were non-pregnant and took oral contraceptives during the study and for at least 2 days before both study days, since cutaneous sensory and vasomotor responses differ throughout the female hormonal cycle [15].

The Committees on Biomedical Research Ethics of the Capital Region of Denmark approved the study (HB2008142). All subjects gave informed consent to participate in the study that was undertaken in accordance with the Helsinki Declaration of 1964, as revised in Edinburgh in 2000 .

\section{Design}

Using a double-blind, placebo-controlled, crossover design all participants were, in a balanced order, randomly allocated to receive injections of PACAP38 and placebo or VIP and placebo (isotonic saline) on two study days separated by at least 2 days. Thus, each participant received two injections each day, active substance in one and placebo in the other arm. One of the investigators (HWS) performed all the experimental procedures, while each subject rested in a supine position on a comfortable bed in a quiet room (temperature of $24-25^{\circ} \mathrm{C}$ ). Prior to provocation participants rested in the supine position for at least $30 \mathrm{~min}$ to reduce influences of experimental conditions on cutaneous blood flow [16]. Likewise, intake of coffee, tea, cocoa, tobacco, methylxanthine-containing foods or beverages was not allowed for the last $4 \mathrm{~h}$ before the study [16].

Spontaneous pain intensity was recorded after the experimental drug injection. Assessment of skin blood flow, flare and wheal were recorded 5, 15 and 20 min after injection of the experimental drug. The validated Danish version of McGill Pain Questionnaire MPQ [17] was used to assess the subjective pain quality and pain distribution.

Intradermal injections

All experimental drugs were prepared, blinded and randomised by the Central Pharmacy, Herlev Hospital, Denmark. The test substrates were $18.1 \mu \mathrm{g} / \mathrm{ml}$ PACAP38 and $13.3 \mu \mathrm{g} / \mathrm{ml}$ VIP (both Calbiochem ${ }^{\circledR}$, Darmstadt, Germany) and the pharmacy produced vials with 200 pmol PACAP38 and 200 pmol VIP. The subjects arm was placed in a comfortable position and $0.05 \mathrm{ml}$ was injected intradermally at an angle of approximately $15^{\circ}$ using a 29 gauge needle (BD Micro-Fine U-100 insulin $0.5 \mathrm{ml}$ syringes, BD Medical, USA). The injection site was the flexor side of the forearm $1 / 3$ distal to the cubital fossa, no more than $1 \mathrm{~cm}$ off midline avoiding visible veins. The injection point was chosen since proximal sites of the human forearm show the most reproducible and robust responses to pain activation [18]. In the opposite arm, the other experimental drug was injected similarly at least $1 \mathrm{~h}$ after the first injection.

Assessment of pain intensity, distribution and quality

Experimental drug-induced pain intensity was recorded continuously every $2 \mathrm{~s}$ on a $10 \mathrm{~cm}$ electronic visual analog scale (VAS), with anchor points $0=$ no pain and $10=$ the worst imaginable pain. Data were collected in a computer for later analysis. Subjects did not see the numeric correlates to their pain perceptions at any point during the study. Experimental drug-induced pain was determined and expressed as area under the VAS-time curve $\left(\mathrm{VAS}_{\mathrm{AUC}}\right.$, $\mathrm{cm} \times \mathrm{min}$ ), peak pain intensity and pain time (total time period of reported pain). When testing and recording of the investigated arm were completed, the subject chose the appropriate descriptor words of the MPQ and was asked to draw the perceived pain distribution on an arm chart. The 
pain distribution area was later quantified by cutting and weighing the pain drawing using an analysis weight (readability $0.1 \mathrm{mg}$, Mettler Toledo AJ 150-L, Greifensee, Switzerland).

\section{Assessment of skin blood flow}

The forearm skin blood flow was measured by laser Doppler flowmetry (LDI, Moor Instruments, Devon, UK). An area of $4 \times 4 \mathrm{~cm}$ was scanned with the injection in the center of the area at a distance of $30 \mathrm{~cm}$ from the skin. The image resolution was obtained at $114 \times 114$ pixels with a scan speed of $4 \mathrm{~ms} /$ pixel. Bandwidth was set at $250 \mathrm{~Hz}$ to $15 \mathrm{kHz}$. Each single scan lasted $69 \mathrm{~s}$. Relative blood flow changes (expressed in \%) were calculated by subtracting the baseline blood flow from blood flow at 5, 15 and 20 min after injection of the experimental drug.

\section{Assessment of flare}

Flare (erythema around the injection site) was identified visually by HWS and mapped 5, 15 and 20 min after the injection on an acetate sheet. The flare areas were subsequently quantified by cutting and weighing the maps on a laboratory weight (readability $0.1 \mathrm{mg}$, Mettler Toledo AJ 150-L, Greifensee, Switzerland).

\section{Assessment of wheal}

The wheal (the area of edema caused by plasma extravasation) was inspected visually and by light palpation by HWS 5, 15 and 20 min after the injection. Afterward the wheal was outlined with a marker pen on transparent removable tape above the wheal and the tape was pasted on millimeter paper and later calculated to total wheal area (in $\mathrm{mm}^{2}$ ).

\section{Statistical analysis}

The pain scores are expressed as median values with quartiles. Other variables are expressed as mean values with standard deviation $( \pm \mathrm{SD})$. PACAP38 was compared to placebo on the opposite arm on the injection day and the same was done for VIP, since it has been shown that armto-arm comparison is more reproducible than period-toperiod comparison [18].

The primary endpoint was difference in the area under VAS-time curve $\left(\mathrm{VAS}_{\mathrm{AUC}}\right)$ between PACAP38 versus placebo, VIP versus placebo and PACAP38 versus VIP. The secondary endpoints were difference in maximum skin blood flow change, flare, wheal and pain distribution between PACAP38 versus placebo, VIP versus placebo and PACAP38 versus VIP. Peak pain intensity and pain time were also obtained but not analyzed statistically. Given that the data were not normally distributed, we performed Friedman's two-way analysis of variance for the four groups: PACAP38, VIP, placebo on VIP day and placebo on PACAP38 day. If the overall $P$ value was less than 0.05 , we applied a post hoc Wilcoxon signed rank test to test the differences between relevant groups for which the significance level $P<0.05$ was also chosen. SPSS (version 16.0) was used for statistical analysis.

\section{Results}

All 16 subjects completed both study days and no data were missing. There were no differences between the two placebo injections for any test variable.

Pain intensity

Pain after PACAP38 and VIP was mild and limited to a short time of about $100 \mathrm{~s}$ after the injection (Fig. 1 and Table 1).

The Friedman's two-way analysis of variance revealed that the $\mathrm{VAS}_{\mathrm{AUC}}$ depended on the injected substance $(P<0.001)$. Post hoc analysis showed that the $\mathrm{VAS}_{\mathrm{AUC}}$ was larger following PACAP38 $(P=0.004)$ and VIP $(P=0.01)$ than after placebo. No statistical difference was found for PACAP38 compared to VIP $(P=0.255)$. The pain distribution area depended on the injected substance $(P<0.001)$. Post hoc analysis revealed that pain distribution area was larger after PACAP38 $(P=0.001)$ and VIP $(P=0.023)$ than after placebo. No statistical difference was found between PACAP38 and VIP $(P=0.215)$. Peak pain intensity and pain time are shown in Table 1 .

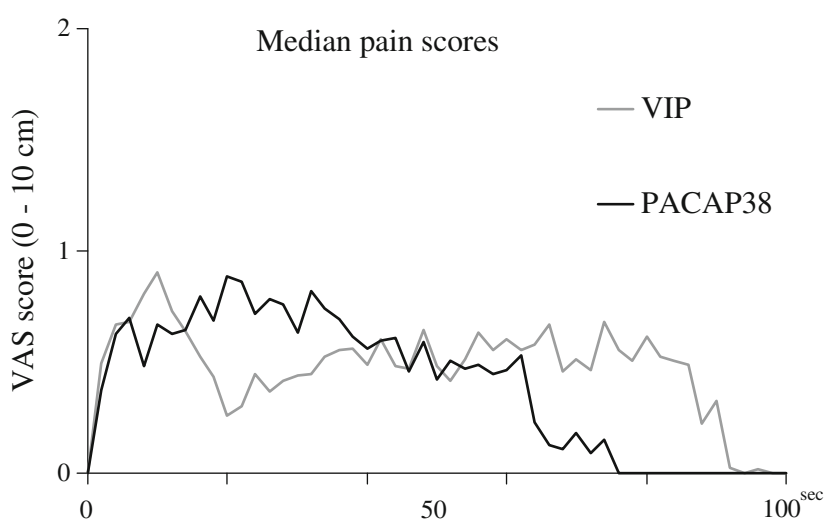

Fig. 1 Median pain scores following injection of 200 pmol VIP and 200 pmol PACAP38. Median pain score did not exceed 0 on any placebo day. Area under VAS-time curve was larger following VIP $(P=0.01)$ and PACAP38 $(P=0.004)$ compared to placebo 
Table 1 Median values with quartiles, except pain distribution as mean $( \pm \mathrm{SD})$

\begin{tabular}{llll}
\hline & VIP & PACAP38 & Placebo \\
\hline VAS $_{\mathrm{AUC}}(\mathrm{cm} \times \mathrm{s})$ & $1.2(0.6-1.7)^{*}$ & $1.0(0.4-1.6)^{*}$ & $0.2(0-0.4)$ \\
$\begin{array}{l}\text { Pain distribution } \\
\text { area }\left(\mathrm{cm}^{2}\right)\end{array}$ & $5.3 \pm 8.0^{*}$ & $2.9 \pm 5.3^{*}$ & $1.6 \pm 3.5$ \\
$\begin{array}{l}\text { Peak pain (VAS) } \\
\text { Pain time (s) }\end{array}$ & $1.3(0.9-2.8)$ & $1.7(1.0-2.2)$ & $0.5(0-1.2)$ \\
\hline
\end{tabular}

$V A S_{A U C}$ area under VAS-time curve, $* P<0.05$ for active drug versus placebo

Placebo values are shown as a mean of placebo on VIP and PACAP38 day

Peak pain and time were not analyzed statistically

Table 2 Words chosen by $30 \%$ and more of subjects in the McGill Pain Questionnaire (MPQ)

\begin{tabular}{llllll}
\hline VIP & $\%$ & PACAP38 & $\%$ & Placebo & $\%$ \\
\hline Boring & 44 & Boring & 56 & Boring & 41 \\
Annoying & 31 & Sharp & 31 & Tender & 41 \\
& & Taut & 38 & & \\
\hline
\end{tabular}

The most frequent descriptor words in the MPQ after injections are listed in Table 2.

\section{Skin Blood flow change}

The increase in skin blood flow depended on the injected substance $(P<0.001)$ (Figs. 2 and 3$)$. Post hoc analysis revealed a maximal increase in skin blood flow after PACAP38 and VIP 5 min after injection, which was larger than compared to placebo $(P<0.001)$. VIP induced a larger maximal increase in skin blood flow than PACAP38 $(P=0.002)$.

\section{Visible flare}

The flare area depended on the injected substance $(P<0.001)$ (Fig. 3). Post hoc analysis revealed a maximal flare area 5 min after PACAP38, which was larger compared to placebo $(P<0.001)$. The maximal flare area following VIP also occurred 5 min after injection and was larger compared to placebo $(P<0.001)$. VIP induced a larger maximal flare area than PACAP38 $(P=0.001)$ at 5 min after injection.

\section{Wheal}

The wheal area depended on the injected substance $(P<0.001)$ (Fig. 3). Post hoc analysis revealed a maximal wheal area $20 \mathrm{~min}$ after PACAP38, which was larger compared to placebo $(P=0.011)$. The maximal wheal area after VIP also occurred 20 min after injection and was larger compared to placebo $(P=0.001)$. The VIP-induced wheal area was larger than PACAP38-induced wheal $(P=0.001)$ at $20 \mathrm{~min}$ after injection.

Study safety

The volunteers tolerated the intradermal experimental drug injections to the forearm well and no adverse events or complaints were reported.

\section{Discussion}

PACAP38 and VIP both evoked cutaneous pain, increased blood flow and flare (neurogenic inflammation) as well as wheal (mast cell degranulation). Surprisingly, PACAP38 induced mild short-lasting pain that was not different from VIP-induced pain. Furthermore, VIP induced more blood flow, flare and wheal than PACAP38. These data indicate that the PAC1 receptor activation is not involved in acute pain, neurogenic inflammation and mast cell degranulation.

\section{Localization of receptors and nociceptors}

Nociceptors are present in the human epidermis and dermis, along the wall of blood vessels, around sweat glands and hair follicles $[19,20]$. Immunohistochemical studies have shown that PACAP38- and VIP-immunoreactive nerve fibers are present in human skin close to mast cells, sweat glands and hair follicles [20-24]. The peptides have equal affinity for the VPAC1 and VPAC2 receptors, but only PACAP activates the PAC1 receptor. VPAC1 and VPAC2 receptors have been visualized on dermal vessel walls $[25,26]$ and the $\mathrm{PAC1}$ receptor has been identified in skin tissue [23]. So far, however, no studies have attempted to identify VIP/PACAP receptors on human sensory dermal nociceptors. Human skin mast cells express higher levels of VPAC2 mRNA compared to VPAC1 mRNA [22]. Collectively, these data suggest that PACAP38 and VIP might have modulatory effects on nociceptive processing in the human skin.

PACAP38 and VIP induced cutaneous pain

To our knowledge, this study is the first to explore differences in pain responses between PACAP38 and VIP. We found that intradermal injection of PACAP38 and VIP induced pain to an equal degree. One study reported that intradermal injection of 150 pmol VIP evoked pain [27], but pain intensity was not precisely described. In the present study the pain area was larger after PACAP38 and VIP than placebo. This may suggest activation of nociceptors, with larger receptive fields than nociceptors 
Fig. 2 Example of flow responses measured with laser Doppler flowmetry to placebo, 200 pmol PACAP38 and 200 pmol VIP in one subject
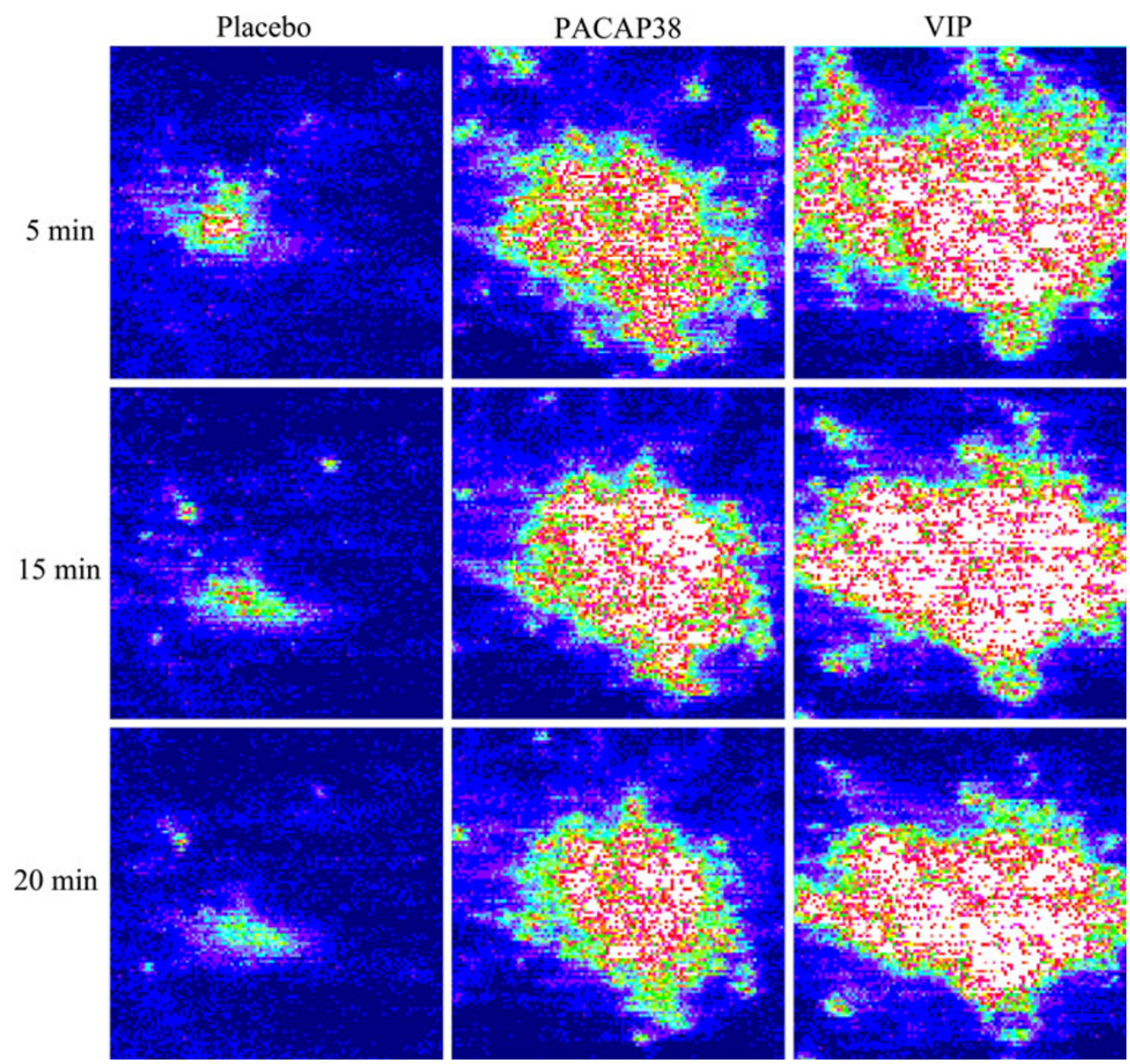

activated by placebo. Surprisingly, our study revealed no difference in pain perception between PACAP38 and VIP. Given that PACAP38 induces more headache than VIP and response properties of cutaneous and dural nociceptors seem similar $[10,11]$ we expected more pain after PACAP38 than after VIP. This would have indicated that the PAC1 receptor plays a key role in nociceptive processing of sensory afferents and explain the difference in head pain responses. One limitation of the present study was that we did not examine the dose response effects of PACAP38 and VIP. However, neuropeptides implicated in migraine pathogenesis have usually been investigated in cutaneous pain models in the range of 50-500 pmol [28-30] and were shown to be suitable dosages when investigating pain, wheal and flare.

VIP- and PACAP38-induced blood flow,

flare and wheal

Intradermal injection of VIP induces histamine release in human skin in vivo measured with microdialysis technique [31] and produces both a wheal and flare reaction within a few minutes of similar degree as in our study [27, 32, 33]. In contrast, intradermal capsaicin injection induces flare, but not wheal [34]. Topical capsaicin pre-treatment inhibits neurogenic inflammation (shown as flare) by depletion of nociceptors [13]. This robustly inhibits VIP induced skin flare, but does not affect the wheal reaction, which therefore most likely is caused by mast cell degranulation [13]. Thus, VIP is likely to induce neurogenic inflammation and mast cell degranulation via two different mechanisms. In the present study we found that VIP increased skin blood flow and flare more than PACAP38, which is in agreement with a previous study [35]. Intradermal histamine injection induces increased skin wheal [36]. PACAP38 causes histamine release in human skin, but much less than compared to VIP and PACAP27 [24]. Thus, these data explain the larger wheal area following VIP injection compared to PACAP38. At present we cannot exclude that VIP and PACAP could induce receptor-independent direct activation of mast cells, which have been suggested in an animal model [37], and might explain the differences in wheal responses.

Present study in relation to VIP and PACAP38 models of migraine

We acknowledge possible physiological differences in tissue responses and therefore the extrapolation of data 
VIP

$\square$ Placebo VIP day

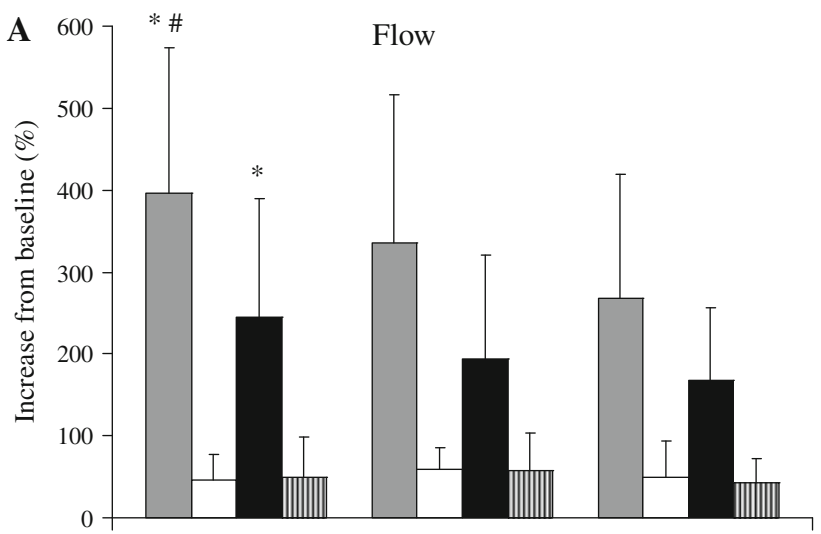

B

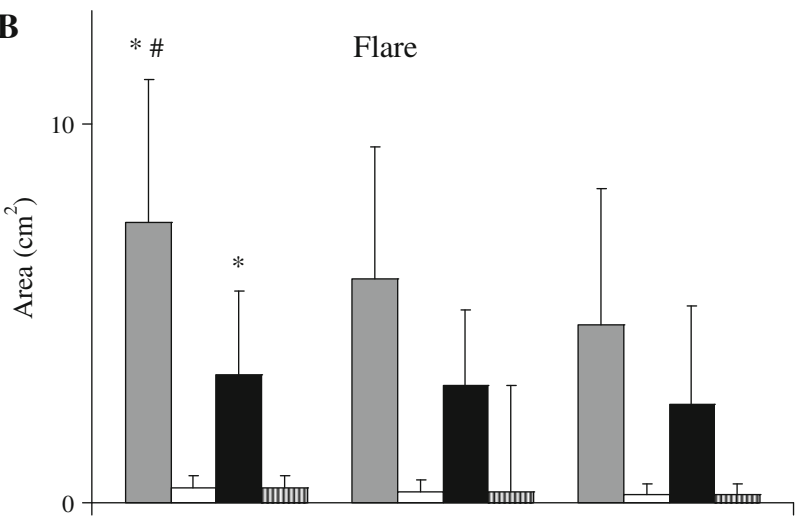

C

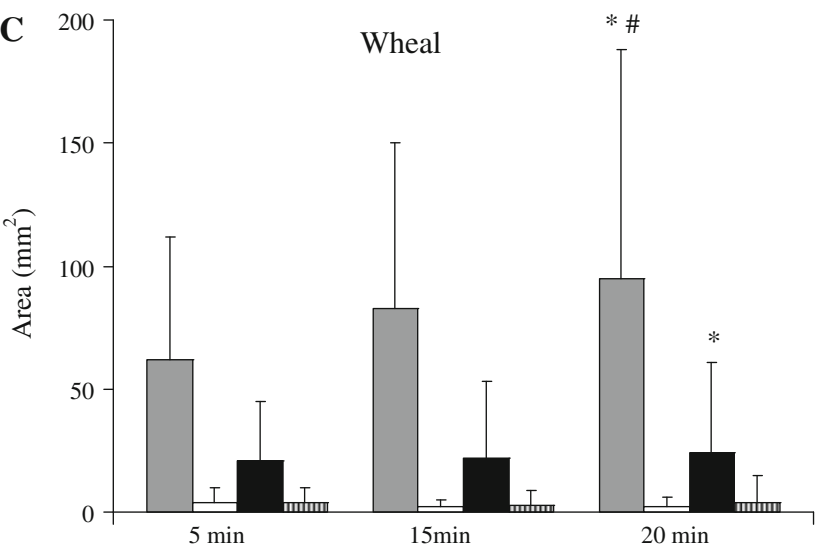

Fig. 3 a Increase from baseline (in \%) in cutaneous blood flow measured with laser Doppler flowmetry. b Flare area (in $\mathrm{cm}^{2}$ ) after injection of experimental drug. $\mathbf{c}$ Wheal area (in $\mathrm{mm}^{2}$ ) after injection of experimental drug. $* P<0.05$ for active drugs versus placebo; \# $P<0.05$ for VIP versus PACAP38. Error lines are $+1 \mathrm{SD}$

from cutaneous model into intravenous models of migraine is critical. Activation and sensitization of dural nociceptors may play a key role in generation of head and migraine pain $[38,39]$. As dural nociceptors have properties similar to the skin nociceptors $[10,11]$ the human skin seems to be a suitable compartment for human in vivo investigations of neuropeptides involved in neurovascular headaches. Furthermore, the present human model of acute cutaneous pain is a well validated model [18, 40], suitable to test and compare pain mechanisms in an isolated area under controlled conditions.

We have previously proposed that $\mathrm{PAC} 1$ receptor activation is a likely mechanism of PACAP38-induced delayed migraine-like attacks [9]. In the present study the induction of cutaneous pain, apparent neurogenic inflammation and mast cell degranulation all seem to be driven by VPAC receptor activation. Such mechanisms may contribute to pain during spontaneous and experimental migraine attacks [41-43]. This raises the question as to why VIP infusion does not induce delayed headaches and migraine-like attacks?

In the present study 200 pmol of PACAP38 or VIP injected at a single point into the dermis induced shortlasting pain. This was caused by a high local concentration of peptides in the dermis, which cannot be expected to be reached when $200 \mathrm{pmol} / \mathrm{kg}$ PACAP38 or VIP are intravenously infused. In human experimental migraine studies, it is very rare that an experimental drug induces pain elsewhere than the head [8, 44-48]. Thus, cephalic vessels are either surrounded by nociceptors with different and more sensitive properties than in other organs, or headache is caused by other mechanisms. It would be interesting to examine a group of migraine patients, to explore if cutaneous pain responses differ between migraineurs and healthy controls.

Various signaling molecules, such as CGRP and prostaglandin $\mathrm{I}_{2}$, do not induce neurogenic inflammation in human skin models [30, 32], but are known to induce migraine-like attacks [45, 49]. Mast cell degranulation may also play a role in migraine pathogenesis $[50,51]$. Yet, VIP only showed a modest $(10 \%)$ effect on histamine release in rat dura mater [52]. More neurogenic inflammation and mast cell degranulation after VIP than after PACAP38 question these phenomena as causative in PACAP38induced delayed migraine-like attacks. Thus, PACAP38 might induce a yet unknown cascade of events taking hours to result in migraine-like attacks, which are probably driven by $\mathrm{PAC} 1$ receptor activation.

\section{Conclusion}

Intradermal injections of PACAP38 and VIP in the forearm of human volunteers evoked equal pain responses. Interestingly, VIP induced larger blood flow and flare as well as wheal responses as compared to PACAP38. This suggests VPAC receptor activation as causative for acute pain, neurogenic inflammation and mast cell degranulation in a human model of cutaneous pain. 
Acknowledgments The authors wish to thank lab technicians Winnie Grønning Nielsen and Lene Elkjær for their excellent and dedicated assistance with data processing. The study was supported by the Lundbeck Foundation via the Lundbeck Foundation Center for Neurovascular Signaling (LUCENS).

Conflict of interest None.

\section{References}

1. Dickinson T, Fleetwood-Walker SM (1999) VIP and PACAP: very important in pain? Trends Pharmacol Sci 20:324-329

2. Dickson L, Aramori I, Sharkey J, Finlayson K (2006) VIP and PACAP receptor pharmacology: a comparison of intracellular signaling pathways. Ann N Y Acad Sci 1070:239-242

3. Arimura A, Somogyvari-Vigh A, Miyata A, Mizuno K, Coy DH, Kitada C (1991) Tissue distribution of PACAP as determined by RIA: highly abundant in the rat brain and testes. Endocrinology 129:2787-2789

4. Ghatei MA, Takahashi K, Suzuki Y, Gardiner J, Jones PM, Bloom SR (1993) Distribution, molecular characterization of pituitary adenylate cyclase-activating polypeptide and its precursor encoding messenger RNA in human and rat tissues. J Endocrinol 136:159-166

5. Hannibal J, Mikkelsen JD, Clausen H, Holst JJ, Wulff BS, Fahrenkrug J (1995) Gene expression of pituitary adenylate cyclase activating polypeptide (PACAP) in the rat hypothalamus. Regul Pept 55:133-148

6. Mikkelsen JD, Hannibal J, Fahrenkrug J, Larsen PJ, Olcese J, McArdle C (1995) Pituitary adenylate cyclase activating peptide38 (PACAP-38), PACAP-27, and PACAP related peptide (PRP) in the rat median eminence and pituitary. J Neuroendocrinol 7:47-55

7. Hansen JM, Sitarz J, Birk S, Rahmann AM, Oturai PS, Fahrenkrug $\mathbf{J}$ et al (2006) Vasoactive intestinal polypeptide evokes only a minimal headache in healthy volunteers. Cephalalgia 26:992-1003

8. Rahmann A, Wienecke T, Hansen JM, Fahrenkrug J, Olesen J, Ashina M (2008) Vasoactive intestinal peptide causes marked cephalic vasodilation, but does not induce migraine. Cephalalgia 28:226-236

9. Schytz HW, Birk S, Wienecke T, Kruuse C, Olesen J, Ashina M (2009) PACAP38 induces migraine-like attacks in patients with migraine without aura. Brain 132:16-25

10. Roosterman D, Goerge T, Schneider SW, Bunnett NW, Steinhoff M (2006) Neuronal control of skin function: the skin as a neuroimmunoendocrine organ. Physiol Rev 86:1309-1379

11. Strassman AM, Levy D (2006) Response properties of dural nociceptors in relation to headache. J Neurophysiol 95:12981306

12. Schmelz M, Michael K, Weidner C, Schmidt R, Torebjork HE, Handwerker HO (2000) Which nerve fibers mediate the axon reflex flare in human skin? Neuroreport 11:645-648

13. Anand P, Bloom SR, McGregor GP (1983) Topical capsaicin pretreatment inhibits axon reflex vasodilatation caused by somatostatin and vasoactive intestinal polypeptide in human skin. Br J Pharmacol 78:665-669

14. Raud J, Dahlen SE, Smedegard G, Hedqvist P (1989) An intravital microscopic model for mast cell-dependent inflammation in the hamster cheek pouch. Acta Physiol Scand 135:95-105

15. Gazerani P, Andersen OK, Arendt-Nielsen L (2005) A human experimental capsaicin model for trigeminal sensitization. Gender-specific differences. Pain 118:155-163
16. Fullerton A, Fischer T, Lahti A, Wilhelm KP, Takiwaki H, Serup J (1996) Guidelines for measurement of skin colour and erythema. A report from the Standardization Group of the European Society of Contact Dermatitis. Contact Dermatitis 35:1-10

17. Drewes AM, Helweg-Larsen S, Petersen P, Brennum J, Andreasen A, Poulsen LH, Jensen TS (1993) McGill Pain Questionnaire translated into Danish: experimental and clinical findings. Clin J Pain 9:80-87

18. Van der Schueren BJ, de Hoon JN, Vanmolkot FH, Van Hecken A, Depre M, Kane SA et al (2007) Reproducibility of the capsaicin-induced dermal blood flow response as assessed by laser Doppler perfusion imaging. Br J Clin Pharmacol 64:580-590

19. Dalsgaard CJ, Rydh M, Haegerstrand A (1989) Cutaneous innervation in man visualized with protein gene product 9.5 (PGP 9.5) antibodies. Histochemistry 92:385-390

20. Schulze E, Witt M, Fink T, Hofer A, Funk RH (1997) Immunohistochemical detection of human skin nerve fibers. Acta Histochem 99:301-309

21. Savage MV, Brengelmann GL, Buchan AM, Freund PR (1990) Cystic fibrosis, vasoactive intestinal polypeptide, and active cutaneous vasodilation. J Appl Physiol 69:2149-2154

22. Groneberg DA, Welker P, Fischer TC, Dinh QT, Grutzkau A, Peiser C et al (2003) Down-regulation of vasoactive intestinal polypeptide receptor expression in atopic dermatitis. J Allergy Clin Immunol 111:1099-1105

23. Steinhoff M, McGregor GP, Radleff-Schlimme A, Steinhoff A, Jarry H, Schmidt WE (1999) Identification of pituitary adenylate cyclase activating polypeptide (PACAP) and PACAP type 1 receptor in human skin: expression of PACAP-38 is increased in patients with psoriasis. Regul Pept 80:49-55

24. Odum L, Petersen LJ, Skov PS, Ebskov LB (1998) Pituitary adenylate cyclase activating polypeptide (PACAP) is localized in human dermal neurons and causes histamine release from skin mast cells. Inflamm Res 47:488-492

25. Lundeberg L, Nordlind K (1999) Vasoactive intestinal polypeptide in allergic contact dermatitis: an immunohistochemical and radioimmunoassay study. Arch Dermatol Res 291:201-206

26. Fischer TC, Dinh QT, Peiser C, Loser C, Fischer A, Groneberg DA (2002) Simultaneous detection of receptor mRNA and ligand protein in human skin tissues. J Cutan Pathol 29:65-71

27. Rukwied R, Heyer G (1999) Administration of acetylcholine and vasoactive intestinal polypeptide to atopic eczema patients. Exp Dermatol 8:39-45

28. Jensen K, Tuxen C, Pedersen-Bjergaard U, Jansen I, Edvinsson L, Olesen J (1990) Pain, wheal and flare in human forearm skin induced by bradykinin and 5-hydroxytryptamine. Peptides 11:1133-1138

29. Pedersen-Bjergaard U, Nielsen LB, Jensen K, Edvinsson L, Jansen I, Olesen J (1989) Algesia and local responses induced by neurokinin $\mathrm{A}$ and substance $\mathrm{P}$ in human skin and temporal muscle. Peptides 10:1147-1152

30. Pedersen-Bjergaard U, Nielsen LB, Jensen K, Edvinsson L, Jansen I, Olesen J (1991) Calcitonin gene-related peptide, neurokinin A and substance P: effects on nociception and neurogenic inflammation in human skin and temporal muscle. Peptides $12: 333-337$

31. Huttunen M, Harvima IT, Ackermann L, Harvima RJ, Naukkarinen A, Horsmanheimo M (1996) Neuropeptide- and capsaicin-induced histamine release in skin monitored with the microdialysis technique. Acta Derm Venereol 76:205-209

32. Brain SD, Tippins JR, Morris HR, MacIntyre I, Williams TJ (1986) Potent vasodilator activity of calcitonin gene-related peptide in human skin. J Invest Dermatol 87:533-536

33. Fjellner B, Hagermark O (1981) Studies on pruritogenic and histamine-releasing effects of some putative peptide neurotransmitters. Acta Derm Venereol 61:245-250 
34. Sikand P, Shimada SG, Green BG, LaMotte RH (2009) Similar itch and nociceptive sensations evoked by punctate cutaneous application of capsaicin, histamine and cowhage. Pain 144:66-75

35. Warren JB, Cockcroft JR, Larkin SW, Kajekar R, Macrae A, Ghatei MA, Bloom SR (1992) Pituitary adenylate cyclase activating polypeptide is a potent vasodilator in humans. J Cardiovasc Pharmacol 20:83-87

36. Hovell CJ, Beasley CR, Mani R, Holgate ST (1987) Laser Doppler flowmetry for determining changes in cutaneous blood flow following intradermal injection of histamine. Clin Allergy 17:469-479

37. Seebeck J, Kruse ML, Schmidt-Choudry A, Schmidt WE (1998) Pituitary adenylate cyclase activating polypeptide induces degranulation of rat peritoneal mast cells via high-affinity PACAP receptor-independent activation of $G$ proteins. Ann N Y Acad Sci 865:141-146

38. Burstein R, Yamamura H, Malick A, Strassman AM (1998) Chemical stimulation of the intracranial dura induces enhanced responses to facial stimulation in brain stem trigeminal neurons. J Neurophysiol 79:964-982

39. Strassman AM, Raymond SA, Burstein R (1996) Sensitization of meningeal sensory neurons and the origin of headaches. Nature 384:560-564

40. Gazerani P, Andersen OK, Arendt-Nielsen L (2007) Site-specific, dose-dependent, and sex-related responses to the experimental pain model induced by intradermal injection of capsaicin to the foreheads and forearms of healthy humans. J Orofac Pain 21:289-302

41. Moskowitz MA (1993) Neurogenic inflammation in the pathophysiology and treatment of migraine. Neurology 43:S16-S20

42. Levy D, Burstein R, Kainz V, Jakubowski M, Strassman AM (2007) Mast cell degranulation activates a pain pathway underlying migraine headache. Pain 130:166-176
43. Burstein R, Yarnitsky D, Goor-Aryeh I, Ransil BJ, Bajwa ZH (2000) An association between migraine and cutaneous allodynia. Ann Neurol 47:614-624

44. Wienecke T, Olesen J, Oturai PS, Ashina M (2009) Prostaglandin E2(PGE2) induces headache in healthy subjects. Cephalalgia 29:509-519

45. Lassen LH, Haderslev PA, Jacobsen VB, Iversen HK, Sperling B, Olesen J (2002) CGRP may play a causative role in migraine. Cephalalgia 22:54-61

46. Lassen LH, Thomsen LL, Olesen J (1995) Histamine induces migraine via the H1-receptor. Support for the NO hypothesis of migraine. Neuroreport 6:1475-1479

47. Wienecke T, Olesen J, Oturai PS, Ashina M (2008) Prostacyclin (epoprostenol) induces headache in healthy subjects. Pain 139:106-116

48. Schytz HW, Wienecke T, Olesen J, Ashina M (2009) Carbachol induces headache, but not migraine-like attacks, in migraine without aura patients. Cephalalgia (In press)

49. Wienecke T, Olesen J, Ashina M (2009) Prostaglandin $I_{2}$ (Epoprostenol) triggers migraine-like attacks in migraineurs. Cephalalgia (In Press)

50. Levy D (2009) Migraine pain, meningeal inflammation, and mast cells. Curr Pain Headache Rep 13:237-240

51. Theoharides TC, Donelan J, Kandere-Grzybowska K, Konstantinidou A (2005) The role of mast cells in migraine pathophysiology. Brain Res Brain Res Rev 49:65-76

52. Ottosson A, Edvinsson L (1997) Release of histamine from dural mast cells by substance $\mathrm{P}$ and calcitonin gene-related peptide. Cephalalgia 17:166-174 